\title{
Predators, facilitators, or both? Re-evaluating an apparent predator-prey relationship
}

\author{
Elizabeth M. P. Madin ${ }^{1, *}$, Joshua S. Madin² \\ ${ }^{1}$ Department of Environmental Sciences, University of Technology-Sydney, Sydney, New South Wales 2007, Australia \\ ${ }^{2}$ Department of Biological Sciences, Macquarie University, Sydney, New South Wales 2019, Australia
}

\begin{abstract}
Predators and prey are occasionally observed to comingle in close proximity on coral reefs. Both lethal and non-lethal (i.e. behavioral) effects of predators on prey are well documented. However, observations of apparent predator-prey interactions between the piscivorous twinspot snapper Lutjanus bohar and the herbivorous surgeonfish Acanthurus triostegus suggest that the nature of their association may be context-dependent. The context-dependent nature of some species interactions is well-known, and in some cases a single species has been shown to act as both predator and facilitator to its prey. We present incidental in situ observations suggesting that, in the context of voraciously grazing schools of $A$. triostegus, this species pair may also engage in a facultative mutualistic relationship. Specifically, we propose that within this context, both species may indirectly derive a benefit through changes in the behavior and/or density of territorial damselfishes driven by both $L$. bohar and A. triostegus. We provide prescriptions for rigorously testing this hypothesis and suggest that re-evaluation of this, and possibly other, ostensibly exclusive predator-prey pairs in marine systems may reveal unexpected relationships. Given the relative lack of examples of such interactions involving the same predator acting as both facilitator and predator from marine versus terrestrial systems, coupled with this preliminary evidence, we propose that this topic is ripe for exploration.
\end{abstract}

KEY WORDS: Facilitation - Facultative mutualism - Predator-prey interaction · Coral reef $\cdot$ Fish behavior Resale or republication not permitted without written consent of the publisher

\section{Recognizing the importance of facilitation in ecological communities}

In recent years, ecologists have highlighted the need for re-evaluation of ecological theory through consideration of not only the antagonistic associations traditionally considered to govern the structure of ecological systems (e.g. competition, predation), but also positive, or facilitative, interactions (Stachowicz 2001, Bruno et al. 2003). While many empirical studies have documented facilitative (e.g. mutualistic) interactions between species (reviewed by Stachowicz 2001), only recently has the theoretical framework of modern ecology begun to incorporate these positive species interactions (Bruno et al. 2003). Indeed, in recent decades, ecologists have begun to understand that the net effects of positive interactions are at least as important as those of negative interactions and physical forces in shaping ecological communities (Stachowicz 2001). Importantly, there is a burgeoning recognition among ecologists that the same species pair may engage in both antagonistic (e.g. predatory, competitive) and facilitative (positive) interactions, whether simultaneously or in different contexts (Bruno et al. 2003). Despite this recognition, very few studies have explicitly considered both types of interactions (Bascompte 2010). A counterpoint is the recent study of Thebault \& Fontaine (2010), which compared both types of interactions and found that the network architecture promoting community stability differs dramatically between antagonistic and mutualistic networks. In order to gain a more complete and accurate picture 
of species interactions, and thus the interaction networks that shape ecological communities, consideration of both antagonistic and facilitative interaction components is essential (Bruno et al. 2003, Bascompte 2010). Such an effort will likely require a contextdependent approach, in which the full range of the complexity and variability in species interactions is examined.

\section{A counterintuitive species interaction}

Palmyra Atoll in the central Pacific Ocean provides a rare example of a predator-rich coral reef system (Knowlton \& Jackson 2008). Here, prey species are known to exhibit strong anti-predator behaviors, often at the cost of reduced foraging ranges (Madin et al. 2010a). Fig. 1 is a visual representation of the wellknown 'ecology of fear' concept of non-lethal predator-prey interactions (Brown et al. 1999). Specifically, this photo depicts a 'zone of fear' imposed upon individuals within this school of herbivorous convict surgeonfish Acanthurus triostegus by the predatory twinspot snapper Lutjanus bohar. The widespread, overlapping distributions of these species throughout the tropical Pacific suggest that this and similar inter-

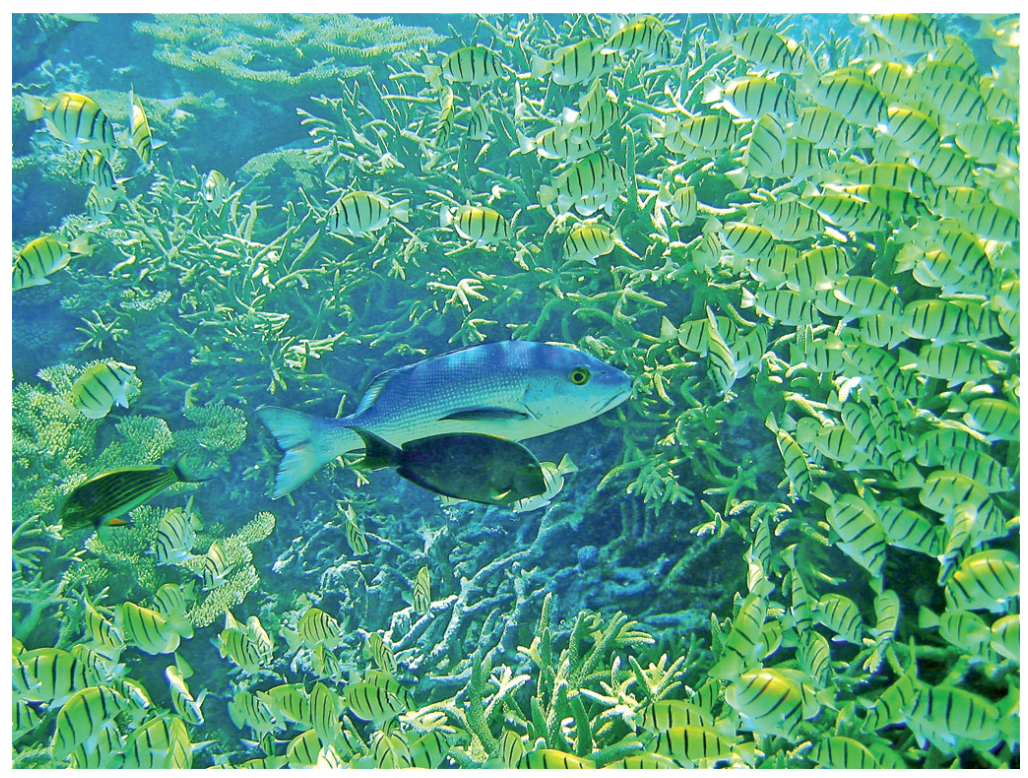

Fig. 1. Lutjanus bohar and Acanthurus triostegus. A piscivorous twinspot snapper hovers amongst a school of herbivorous surgeonfish as it moves over the reef to graze on benthic algae. The 'zone of fear' immediately surrounding the snapper prevents grazing within its immediate vicinity by adjacent surgeonfish, but the snapper simultaneously removes surgeonfish competitors - either through lethal (i.e. consumption) or risk (i.e. hiding) effects thus increasing surgeonfish foraging opportunities. Also present are 2 other acanthurids: A. lineatus (left) and A. xanthopterus (center) actions are common occurrences on coral reefs. Such interactions are understood to have important ecological effects regardless of whether or not prey are actually consumed (Dill et al. 2003, Schmitz et al. 2004), e.g. by affecting the grazing patterns of herbivores (Madin et al. 2010a) and subsequently affecting prey fitness and/or algal distribution (Madin et al. 2010b).

However, this apparent predator-prey pair may also exhibit a different kind of relationship - one of facultative mutualism. While conducting a separate behavioral study (nearly $500 \mathrm{~h}$ of underwater observations made at 11 distinct locations within 3 atoll reef systems; Madin et al. 2010a,b), we came across many instances where a voracious grazing school of hundreds of Acanthurus triostegus individuals moved slowly over the reef like a wave. A small subset of these schools contained one or more large, predatory fishes lurking within them (Fig. 1). As these 'grazing-frenzied' surgeonfish schools moved over the reef to graze on benthic algae, their competitors, territorial herbivorous damselfishes, darted out from the protection of the reef to defend their algal territories. Removal of tertorial damselfishes from their territories has been hown to result in rapid and significant increases in feeding by acanthurids and other roving herbivores (Mahoney 1981, Hourigan 1986), and as such territorial damselfishes are known to strongly influence the foraging behavior and success of their more mobile competitors (Hourigan 1986), such as A. triostegus. During 3 distinct instances where we observed comingled A. triostegus-predator schools (totalling roughly $1 \mathrm{~h}$ of combined observation time), we noted hundreds of such A. triostegus-territorial herbivorous fish competitive interactions. However, emergence from the reef exposes the small, territorial competitors to the piscivorous Lutjanus bohar that hovers nearby within the cover of the A. triostegus school (sensu the 'smokescreen effect' described for spiders; Jackson \& Pollard 1996). While not uncommon occurrences themselves, it is relatively rare to observe predatory attacks in natural reef systems (Sandin \& Pacala 2005). Nonetheless, a relatively large number of attacks by $L$. bohar-and other predatory fishes adopting a similar strategy - were observed on A. triostegus' competitors. We noted 3 attacks on territorial damselfishes by different $L$. bohar individuals and a further 5 attacks by other piscivorous fishes (Cephalopholis argus, Cephalopholis sp., and Cheilinus undulates; although the 
latter, while known to be piscivorous, is unlikely to consume adult acanthurids) over the roughly $1 \mathrm{~h}$ of total observation time. Although at first glance this appears to be a low attack rate, it is far higher than expected based on published background attack rates of coral reef predators on damselfishes in another system (Sandin \& Pacala 2005). In contrast, we observed no attacks by L. bohar on A. triostegus despite close proximity (i.e. tens of centimeters; easy striking distance) of the predator continuously resident within the school for the $1 \mathrm{~h}$ observation time. A distracted or injured $A$. triostegus would be an easy and likely target (Helfrich et al. 1968, Randall 1980), and we noted momentary cessations of feeding by adjacent $A$. triostegus immediately following $L$. bohar attacks on their competitors; however, our observations suggest that in the context of these grazing frenzies, L. bohar (and possibly other piscivores) are far more likely to attack A. triostegus' competitors than A. triostegus themselves. We propose that this may be because $A$. triostegus is providing an unexpected benefit to the predatory L. bohar-flushing out and distracting alternative prey. In return, the $A$. triostegus gain access to the algal patches of their competitors, either because the competitors are eaten by the predator, or because they take refuge in the reef matrix to hide from it.

\section{A context-dependent relationship?}

Lutjanus bohar and Acanthurus triostegus are undoubtedly linked through their well-known predator-prey interactions, and at 2 study sites in particular (Palmyra Atoll and Christmas Island), acanthurids are known to be the dominant fish diet item of $L$. bohar (Helfrich et al. 1968). However, we propose that in at least one set of specific circumstances, this species pair may also engage in a facultatively mutualistic relationship. In the context of $A$. triostegus grazing frenzies, it appears that both species derive a benefit in terms of increased foraging opportunities, despite the slight cost associated with a localized reduction in the grazing area of $A$. triostegus caused by the presence of $L$. bohar (Fig. 1). Although our incidental observations did not allow us to explicitly quantify the net costs and benefits of this interaction, it is logical to assume that if the costs of this interaction outweighed its benefits, $A$. triostegus would disperse and/or move elsewhere over the reef, rather than continue to forage in the immediate presence of a predator (Fig. 1) that is known to rely on acanthurids for a large proportion of its diet (Helfrich et al. 1968). A. triostegus can easily avoid foraging in close proximity to predators; indeed, most potential prey fish individuals on the reef do so by moving elsewhere or taking refuge as predators approach (Madin et al. 2010a). While the latter actions may not always be feasible for an entire school simultaneously, dispersal of the school would render them viable options for predator avoidance.

This example described above provides preliminary evidence that the nature of the Lutjanus boharAcanthurus triostegus interaction may be context-specific. In particular, in most contexts these 2 species are predator and potential prey, but in the context of these grazing frenzies their association may be based more on mutualism than antagonism, allowing both species to derive a benefit from the interaction. The simple observation of the removal (through consumption or retreat) of $A$. triostegus' competitors by $L$. bohar demonstrates a counterintuitive positive, or facilitative, interaction between these species. What remains to be determined are: (1) the value of this benefit relative to the observed non-lethal and potential lethal costs to $A$. triostegus, or the net sign of the interaction, within the context of grazing frenzies; and (2) the relative roles of facilitative and antagonistic interactions in overall relations between these 2 species. Further study is needed to uncover the full range of complexity of the L. bohar-A. triostegus relationship, and indeed those of A. triostegus and other potential predators we observed to engage in similar behavior. A further question remains if future study reveals that these benefits do not, in fact, outweigh costs: Why do A. triostegus continue to forage in such close proximity to their potential predators? Because these grazing schools of $A$. triostegus are common on many coral reefs, and occur both with and without embedded piscivores, potential benefits and/or costs could be assessed by quantifying $A$. triostegus feeding rates in the presence versus absence of piscivores (e.g. via calculating bite rates from focal individual observations: Bellwood 1995; and/or manipulative grazing assays: Hay 1984). Likewise, the costs of localized reductions in A. triostegus foraging opportunity due to cessation of feeding following $L$. bohar attacks on territorial damselfishes could be assessed through A. triostegus bite rate observations before, during, and after attacks. Additionally, focal piscivore observations could elucidate both lethal costs to $A$. triostegus as well as the relative benefit(s) derived by piscivores from consumption of $A$. triostegus versus their site-attached competitors, e.g. via calculating attack rates derived from in situ observation and coupling these with subsequent gut contents analysis (Randall 1967).

\section{Re-evaluating species interactions}

Other studies have drawn on similar opportunistic reports of unpredictable animal behavior to generate 
important hypotheses, such as that of cooperative feeding in crocodilians (Gans 1989, King et al. 1998). Despite their absence of rigorous quantitative support, these types of qualitative observations have led to important advances in our understanding of interaction networks. In an enlightening study in which he suggested that a single species (the peregrine falcon Falco peregrinus) acted as both predator and facilitator (through predation on crows, leading to reduced predation of crows on seabird eggs) for a suite of seabirds, Paine et al. (1990, p. 7) also remarked that 'strong tests of the implied relationships are probably impossible'. The merit of such hypotheses should certainly not be discounted, despite their lack of unequivocal supporting quantitative evidence, if for no other reason than to inspire future workers to test them. Recently, Charter et al. (in press) built on Paine et al.'s (1990) premise and showed through manipulative (nest box) experiments that a single generalist predator species (the raptor Eurasian kestrel Falco tinnunculus) may act as both predator of and a facilitator of breeding success for its passerine prey (the house sparrow Passer domesticus) by likewise reducing crow egg predation.

Understanding the complex nature of the Lutjanus bohar-Acanthurus triostegus relationship requires further study, but our initial observations suggest that re-evaluation of this, and other ostensibly solely predator-prey pairs in marine systems, may reveal unexpected relationships and is therefore ripe for exploration. As Bascompte (2010) points out, only by embracing and exploring both the antagonistic and mutually beneficial facets of species interactions will we develop a fuller understanding of the structure of ecological networks and, thus, how they will ultimately respond to global change.

Acknowledgements. We thank J. Osbourne, M. Readdie, J. Lape, and L. Max for valuable assistance in the field and the staff of the Palmyra Research Station, K. Andersen and staff, R. Bryden and staff, and Norwegian Cruise Lines for logistical field support. Funding was provided by the US National Science Foundation, the US Department of Homeland Security, the National Geographic Society, The Marisla Foundation, the Myers Oceanographic Trust, the Sigma Xi Scientific Research Society, the Worster Family Trust, UCSB Departments of Ecology, Evolution \& Marine Biology and Geography, and the Australian Research Council. We thank S. Madin for helpful discussion and A. Friedlander for taxonomic help. D. Falster and 3 anonymous reviewers provided valuable comments on earlier versions of the manuscript. Finally, we thank the Palmyra Atoll Research Consortium, The Nature Conservancy, the US Fish and Wildlife Service, the Kiribati Ministry of Environment, Lands and Agriculture Development and the citizens of Tabuaeran and Kiritimati Atolls for their support and cooperation.

Editorial responsibility: Matthias Seaman,

Oldendorf/Luhe, Germany

\section{LITERATURE CITED}

Bascompte J (2010) Structure and dynamics of ecological networks. Science 329:765-766

Bellwood DR (1995) Direct estimate of bioerosion by two parrotfish species, Chlorurus gibbus and C. sordidus, on the Great Barrier Reef, Australia. Mar Biol 121:419-429

Brown JS, Laundre JW, Gurung M (1999) The ecology of fear: optimal foraging, game theory, and trophic interactions. J Mammal 80:385-399

> Bruno JF, Stachowicz JJ, Bertness MD (2003) Inclusion of facilitation into ecological theory. Trends Ecol Evol 18:119-125

Charter M, Izhaki I, Leshem Y (in press) Predation or facilitation? An experimental assessment of whether generalist predators affect the breeding success of passerines. J Ornithol

Dill LM, Heithaus MR, Walters CJ (2003) Behaviorally mediated indirect interactions in marine communities and their conservation implications. Ecology 84:1151-1157

Gans C (1989) Crocodilians in perspective. Am Zool 29: 1051-1054

Hay ME (1984) Patterns of fish and urchin grazing on Caribbean coral reefs: are previous results typical? Ecology 65: 446-454

Helfrich PT, Piyakarnchana T, Miles PS (1968) Ciguatera fish poisoning. I. The ecology of ciguateric reef fishes in the Line Islands. Occas Pap Bernice P Bishop Mus 23:305-382

Hourigan TF (1986) An experimental removal of a territorial pomacentrid: effects on the occurrence and behaviour of competitors. Environ Biol Fishes 15:161-169

Jackson RR, Pollard SD (1996) Predatory behavior of jumping spiders. Annu Rev Entomol 41:287-308

King FW, Thorbjarnarson J, Yamashita C (1998) Cooperative feeding: a misinterpreted and under-reported behavior of crocodilians. Fla Mus Nat Hist. Available at www.flmnh. ufl.edu/herpetology/herpbiology/bartram.htm (accessed 15 Jan 2011)

> Knowlton N, Jackson JBC (2008) Shifting baselines, local impacts, and global change on coral reefs. PLoS Biol 6:e54

> Madin EMP, Gaines SD, Warner RR (2010a) Field evidence for pervasive indirect effects of fishing on prey foraging behavior. Ecology 91:3563-3571

Madin EMP, Gaines SD, Madin JS, Warner RR (2010b) Fishing indirectly structures macroalgal assemblages by altering herbivore behavior. Am Nat 176:785-801

Mahoney BM (1981) An examination of interspecific territoriality in the Dusky damselfish, Eupomacentrus dorsopunicans Poey. Bull Mar Sci 31:141-146

Paine RT, Wootton JT, Boersma PD (1990) Direct and indirect effects of peregrine falcon predation on seabird abundance. Auk 107:1-9

Randall JE (1967) Food habits of reef fishes in the West Indies. Stud Trop Oceanogr 5:665-847

Randall JE (1980) A survey of ciguatera at Enewetak and Bikini, Marshall Islands, with notes on the systematics and food-habits of ciguatoxic fishes. Fish Bull 78:201-249

Sandin SA, Pacala SW (2005) Fish aggregation results in inversely density-dependent predation on continuous coral reefs. Ecology 86:1520-1530

Schmitz OJ, Krivan V, Ovadia O (2004) Trophic cascades: the primacy of trait-mediated indirect interactions. Ecol Lett $7: 153-163$

- Stachowicz JJ (2001) Mutualism, facilitation, and the structure of ecological communities. BioScience 51:235-246

Thebault E, Fontaine C (2010) Stability of ecological communities and the architecture of mutualistic and trophic networks. Science 329:853-856

Submitted: August 27, 2010; Accepted: April 7, 2011

Proofs received from author(s): May 31, 2011 